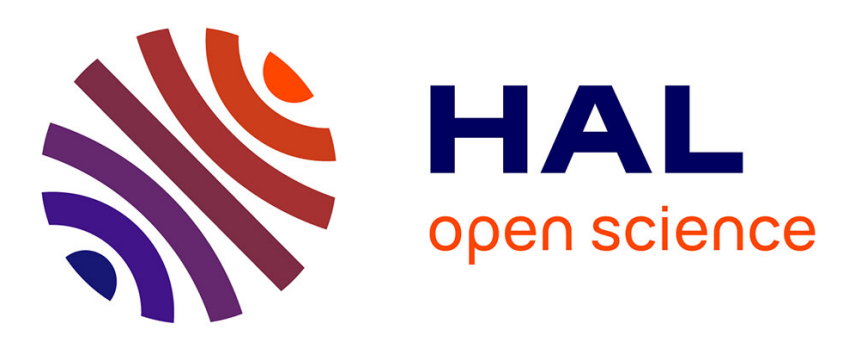

\title{
The investment in time needed for heat treatment of flint and chert
}

\author{
Patrick Schmidt, Céline Paris, Ludovic Bellot-Gurlet
}

\section{To cite this version:}

Patrick Schmidt, Céline Paris, Ludovic Bellot-Gurlet. The investment in time needed for heat treatment of flint and chert. Archaeological and Anthropological Sciences, 2016, 8 (4), pp.839 - 848. $10.1007 / \mathrm{s} 12520-015-0259-\mathrm{y}$. hal-01546571

\section{HAL Id: hal-01546571 \\ https://hal.science/hal-01546571}

Submitted on 20 Jun 2021

HAL is a multi-disciplinary open access archive for the deposit and dissemination of scientific research documents, whether they are published or not. The documents may come from teaching and research institutions in France or abroad, or from public or private research centers.
L'archive ouverte pluridisciplinaire HAL, est destinée au dépôt et à la diffusion de documents scientifiques de niveau recherche, publiés ou non, émanant des établissements d'enseignement et de recherche français ou étrangers, des laboratoires publics ou privés. 
Schmidt P., Paris C., Bellot-Gurlet L. (2016). The investment in time needed for heat treatment of flint and chert, Archaeological and Anthropological Sciences, 8, 839-848.

https://doi.org/10.1007/s12520-015-0259-y

\title{
The investment in time needed for heat treatment of flint and chert
}

\author{
Patrick Schmidt ${ }^{1}$, Céline Paris ${ }^{2}$, Ludovic Bellot-Gurlet ${ }^{2}$
}

1 Department of Prehistory and Quaternary Ecology, Eberhard Karls University of Tübingen, Schloss Hohentübingen, 72070 Tübingen, Germany

2 Sorbonne Universités, UPMC Université Paris 6, MONARIS Bde la Molécule aux Nano-objets: Réactivité, Interactions et Spectroscopies, UMR 8233, UPMC-CNRS, 4 place Jussieu, 75252 Paris Cedex 5, France

\begin{abstract}
In archaeology, heat treatment is the process of intentionally modifying lithic raw materials to improve their knapping quality. Even though the nature and parameters of the thermal transformations in rocks like flint and chert have been the object of several recent studies, the investment in time needed for heat treatment remains poorly investigated. In our study using time-resolved in situ Raman spectroscopy, we investigate the progression of the reaction that drives the thermal transformations of flint and chert. We found that, although parameters like maximum temperature and heating rate are functions of the content of chemically bound water and pore space in the samples, the duration these samples must be held at maximum temperature is shorter than $1 \mathrm{~h}$, regardless of the maximum heating temperature or the mineralogy of the sample. Combining our results with previously published data on other parameters needed for lithic heat treatment, we propose lower and upper limits of the investment in time required for different heating procedures and discuss their relation tothe structure and volume of the heated rocks. The actual duration of heat treatment of flint and chert, as it was practised in different chrono-cultural periods, lies somewhere between $7 \mathrm{~h}$ and 2-3 days depending on the type of flint or chert and theheating environment used.
\end{abstract}

Keywords: Lithic heat treatment, Silica rocks, Chalcedony, Flint, Reaction kinetics, Heat treatment duration, Raman spectroscopy

\section{Introduction}

Heat treatment of lithic raw material is the process of intentionally modifying a rock to improve its knapping quality. The technique was first practiced in southern Africa during the Middle Stone Age (Brown et al. 2009; Mourre et al. 2010; Porraz et al. 2013), and it is known from the European Upper Palaeolithic and Mesolithic (Bordes 1969; Eriksen 2006; Tiffagom 1998), the American Paleo-Indian period (Crabtree and Butler 1964; Wilke et al. 1991) and the European Neolithic (Binder 1984; Léa 2005). Understanding the parameters necessary for conducting heat treatment, like the requiredinvestment in time and resources, has important implications for evaluating the technical complexity of the process or the specific know-how at these periods and is therefore of greatimportance to the study of the lithic chaîne opératoire.

Only silica rocks, like flint, chert and silcrete, benefit from heat-treatment to improve their knapping quality because the thermal transformations in such rocks rely on two characteristics: They contain up to $1 \mathrm{wt} \%$ of chemically bound water in the form of silanol $(\mathrm{SiOH})$ (Flörke et al. 1982; Graetsch et al. 1985; Schmidt et al. 2011), and they contain a network of open pores (Micheelsen 1966; RoquéRosell et al. 2010), most probably intergranular pores (Fukuda et al. 2009), thatcan adsorb fluid water accounting for up to $1 \mathrm{wt} \%$ of the total mass of the rock (Schmidt et al. 2011, 2013b) (i.e. accounting for up to 2.7 vol\% of the rock). When heated, the first chemical reaction that begins at $200{ }^{\circ} \mathrm{C}$ is the loss of $\mathrm{SiOH}$ locatedon pore walls, followed by the gradual loss of silanol located at defect sites within the rock (Schmidt et al. 2011, 2012b, 2013c). 
These surface silanols are "converted" to molecular water through the reaction (Schmidt et al. 2011, 2012b):

$$
\mathrm{Si}-\mathrm{OH} \cdots \mathrm{OH}-\mathrm{Si} \rightarrow \mathrm{Si}-\mathrm{O}-\mathrm{Si}+\mathrm{H}_{2} \mathrm{O}
$$

This reaction results in newly formed $\mathrm{Si}-\mathrm{O}-\mathrm{Si}$ bonds that account for the changing mechanical properties of the rock after heat treatment. The resulting $\mathrm{H}_{2} \mathrm{O}$ is evacuated through the network of open pores. However, reaction (1) progressively reduces the volume of open pores in the rock, hampering more and more the $\mathrm{H}_{2} \mathrm{O}$ evacuation as temperatures rise (Schmidt 2014; Schmidt et al. 2012b). Thus, the maximum heating temperature and speed are functions of the $\mathrm{SiOH}$ content, the volume of "open" pores leading to the surface and the volume of the heated rock (Schmidt 2014). These properties dictate four parameters that need to be considered when estimating the total time needed for heat treatment: (1) the speed of heating or ramp rate, (2) the maximum temperature, (3) the time the rock must be held at the maximum temperature to sufficiently modify its mechanical properties and (4) the cooling rate. The mechanisms and constraints influencing parameters (1) and (2) begin to be well understood for flint, chert (Roqué-Rosell et al. 2010; Schmidt 2014; Schmidt et al. 2011) and silcrete (Mercieca 2000; Mercieca and Hiscock 2008; Schmidt et al. 2013b), but parameters (3) and (4) remain poorly investigated. In this work, we investigate parameter (3) for chalcedony-rich rocks like flint and chert and discuss the role of all four parameters to draw a comprehensive picture of the investment in time needed for heat treatment. For evaluating the minimum required duration of heat treatment, we use time-resolved temperature in situ Raman spectroscopy for investigating the kinetics of reaction (1). Our approach sheds light on the reaction kinetics of the thermal transformations of flint and chert heated to different temperatures and consequently will allow a better understanding of the time necessary for their heat treatment.

\section{The measurement of reaction kinetics by in situ Raman spectroscopy}

In accordance with the model of thermal transformations of silica rocks (Schmidt et al. 2012b, 2013b), the time a rock must be held at the maximum heat treatment temperature can be expected to depend on the kinetics of reaction (1). Using in situ transmission infrared spectroscopy, Fukuda and Nakashima (2008) found that, in hydrothermal chalcedony, the dehydration of $\mathrm{SiOH}$ was essentially terminated after $50 \mathrm{~min}$ of heating at $550{ }^{\circ} \mathrm{C}$. This result indicates that rather short periods of heating may produce a large effect in the rocks. Two questions arise in view of these results: (1) Is the $\mathrm{SiOH}$ dehydration kinetics in sedimentary chalcedony of flint and chert the same as the one in hydrothermal chalcedony, and (2) is the reaction kinetics temperature-dependant (i.e. is the time needed at the maximum heating temperature the same at different temperatures)?

We investigate these questions using the measurement of the Raman-active Si-O vibration in $\mathrm{SiOH}$ at $503 \mathrm{~cm}^{-1}$ (Schmidt et al. 2012a). Non-bridging $\mathrm{Si}-\mathrm{O}$ is lost during reaction (1) when bridging $\mathrm{Si}-\mathrm{O}-\mathrm{Si}$ is formed. The timeresolved measurement of the decrease of the Si-O Raman-band is therefore a direct measure of the kinetics of reaction (1). A potential problem with measurements of the $503 \mathrm{~cm}^{-1}$ silanol Raman-band in chalcedony, chert and flint (Schmidt et al. 2012a, 2014) is that it is prone to confusion with a Raman-active moganite lattice-band at $500-501 \mathrm{~cm}^{-1}$ (Götze et al. 1998; Kingma and Hemley 1994; Schmidt et al. 2014). Moganite is a $\mathrm{SiO}_{2}$ polymorph frequently occurring together with quartz in silica rocks like flint and chert (Flörke et al. 1984; Heaney and Post 1992), and it is not always straightforward to separate moganite and $\mathrm{SiOH}$ content in such rocks using Raman spectroscopy (Schmidt et al. 2014). However, moganite is thermally stable up to 900-1000 ${ }^{\circ} \mathrm{C}$ (Flörke et al. 1984; Miehe and Graetsch 1992) whereas $\mathrm{Si}-\mathrm{OH}$ is gradually lost above $200^{\circ} \mathrm{C}$ (Fukuda and Nakashima 2008; Schmidt et al. 2011, 2012a). The moganite band remains stable, whereas the $\mathrm{Si}-\mathrm{O}$ band diminishes gradually during heating treatment. Thus, the measurement of the time-resolved evolution of the $503 \mathrm{~cm}^{-1}$ band intensity at constantly held temperatures (as long as these remain below $900^{\circ} \mathrm{C}$ ) only expresses the loss of $\mathrm{Si}-\mathrm{OH}$ and consequently the formation of new bridging $\mathrm{Si}-\mathrm{O}-\mathrm{Si}$. Unlike thermogravimetric analyses, these measurements are independent of the volume of the samples and the $\mathrm{H}_{2} \mathrm{O}$ diffusion through the rock's porosity because the measured Raman spectra reflect the state at the surface of the samples and molecular water has no influence on the measurements.

\section{Samples and experimental protocol}

\section{Samples and sample preparation}

We selected three samples of flint and chert of different geo-logical age and provenance (Table 1) representing different structural and mineralogical features (see "Results and discussion"). These correspond to widely distributed good-quality raw materials that were used for stone knapping during pre- and proto-historic periods when lithic heat treatment played an important role (Aubry et al. 1998; Léa 2005). One standard thin section was cut from each sample for petro-graphic investigation and one $\approx 600 \mu \mathrm{m}$ thick slab (diamond polished on both sides) was cut for $\mathrm{SiOH}$ measurements using near infrared spectroscopy (NIR). For time-resolved in situ Raman measurement, a chip of $\approx 4 \times 4 \mathrm{~mm}$ was broken off from each slab after an initial NIR measurement. 
Table 1: Sample descriptions, origins and measurement parameters.

\begin{tabular}{|c|c|c|c|c|c|}
\hline $\begin{array}{l}\text { Sample } \\
\text { number }\end{array}$ & Description and origin & SiOH content & $\mathrm{H}_{2} \mathrm{O}$ content & Pore volume & Measurement temperatures \\
\hline PS-09-04 & $\begin{array}{l}\text { Black flint from the chalk cliffs of } \\
\text { Étretat, France. Coniacian. }\end{array}$ & $0.58 w t \%$ & $0.56 w t \%$ & 0.75 vol\% & $\begin{array}{l}250,300 \text { and } 400{ }^{\circ} \mathrm{C} \text { for } 360 \\
\min ; 600^{\circ} \mathrm{C} \text { for } 240 \mathrm{~min}\end{array}$ \\
\hline PS-09-25 & $\begin{array}{l}\text { Reddish brown flint from a clay } \\
\text { and sand deposit, } 3 \mathrm{~km} \text { north-west } \\
\text { of Le Grand-Pressigny, France. } \\
\text { Upper Turonian. }\end{array}$ & 0.69 wt $\%$ & $0.42 w t \%$ & 0.83 vol\% & $\begin{array}{l}300^{\circ} \mathrm{C} \text { for } 360 \mathrm{~min} ; 400 \text { and } \\
500^{\circ} \mathrm{C} \text { for } 240 \mathrm{~min} ; 600^{\circ} \mathrm{C} \text { for } \\
780 \mathrm{~min}\end{array}$ \\
\hline VC-12-01 & $\begin{array}{l}\text { Light-brown to yellowish chert from } \\
\text { solid limestone, Malaucène, } \\
\text { France. Barremian to lower Abtian. }\end{array}$ & $0.56 w t \%$ & $0.33 w t \%$ & 0.65 vol\% & $\begin{array}{l}250,300,400 \text { and } 500{ }^{\circ} \mathrm{C} \text { for } \\
240 \mathrm{~min}\end{array}$ \\
\hline
\end{tabular}

\section{Instruments, settings and signal treatment}

In order to estimate the moganite content of the samples, $X$-ray powder diffraction measurements were carried out on a Bruker D2 PHASER device (spinning sample holder, $\mathrm{CuK} \alpha$, no incident beam monochromator, diffraction diagrams between 0 and $65^{\circ} 2 \theta$, step size 0.2 s/degree). Rietveld refinement of the diffraction data to estimate the moganite and quartz contents was performed using the Maud software (Lutterotti 2010). Structural parameters at room temperature were taken from Will et al. (1988) for $\alpha$-quartz and Heaney and Post (2001) for moganite.

In order to investigate the sample's silanol and $\mathrm{H}_{2} \mathrm{O}$ contents, we recorded near infrared spectra before the chips for the Raman measurements were broken off the slabs. These spectra were acquired with a Bruker VECTOR 22 FTIR spectrometer by means of direct transmission (between 4800 and $4200 \mathrm{~cm}^{-1}$, resolution of $8 \mathrm{~cm}^{-1}$ ). Water contents were determined using the linear $\mathrm{H}_{2} \mathrm{O}$-absorption coefficient $\left(\alpha=1.14 \mathrm{~L} \mathrm{~mol}^{-1} \mathrm{~cm}^{-1}\right.$ ) (Scholze 1960) applied to the $\mathrm{H}_{2} \mathrm{O}$ combination band near $5430 \mathrm{~cm}^{-1}$, and hydroxyl contents were measured through the intensity of the $\mathrm{Si}-\mathrm{OH}$ combination band near $4500 \mathrm{~cm}^{-1}$ (Flörke et al. 1982) using the integral absorption coefficient of $\alpha=160 \mathrm{~L} \mathrm{~mol}^{-1} \mathrm{~cm}^{-2}$ given in Scholze (1960). However, the so-calculated $\mathrm{SiOH}$ contents must be considered as indication only because the used a value was determined for silanol in glass and not for sedimentary chalcedony. Refinement of the absorption coefficient of the NIR silanol-band in flint awaits further studies. The comparison of the silanol contents in the three samples is nonetheless significant because the same (imprecise) absorption coefficient was used for all of them. The volume of intergranular porosity was calculated as follows: First, pore-water at maximum saturation of the samples' pore space was calculated according to the method described in Schmidt et al. (2011), and then, this pore-water content was converted to vol\% using the density of quartz: $2.62 \mathrm{~g} / \mathrm{cm}^{3}$.

The kinetics of the $\mathrm{SiOH}$ loss, and consequently the formation of Si-O-Si, was measured by Raman spectroscopy. Spectra were acquired with a Horiba Jobin Yvon HR800 spectrometer equipped with edge filters (exciting wavelength $457 \mathrm{~nm}, \mathrm{Ar}^{+}$laser, 1800 lines $/ \mathrm{mm}$ grating resulting in a resolution of $\approx 2 \mathrm{~cm}^{-1}$, spectra recorded between 350 and $550 \mathrm{~cm}^{-1}$ ). Spectrometer calibration was set using the $520.5 \mathrm{~cm}^{-1}$ band of a Si crystal. The measurements were made in situ using a heating-stage (Linkam TS1500) with a $\times 50$ long working distance objective. The effective laser power at the exit of the objective was $3 \mathrm{~mW}$ for the 250,300 and $400{ }^{\circ} \mathrm{C}$ measurements of PS-09-04 and the $300{ }^{\circ} \mathrm{C}$ measurement of PS-09-25 and $10 \mathrm{~mW}$ for all other measurements. Acquisition times for spectra ranged between $40 \mathrm{~s}$ and $1 \mathrm{~min}$. In order to quantitatively investigate the timeresolved behaviour of the $\mathrm{SiOH}$ Raman band, the intensity of the $503 \mathrm{~cm}^{-1}$ band was normalised relative to the $464 \mathrm{~cm}^{-1}$ quartz band by calculating the ratio between the integral band intensities of both bands. These intensities were extracted from best fit models of the spectra, using a Lorentzian function for the $464 \mathrm{~cm}^{-1}$ quartz band and a pseudo-Voigt function for the $503 \mathrm{~cm}^{-1}$ band. Error bars were estimated based on the dispersion of the data points for 20 repeated measurements in the same conditions. The measurements acquired with a $10 \mathrm{~mW}$ output of the exciting laser show lesser dispersion and smaller error because of the higher band intensities obtained.

\section{Time-resolved high-temperature measurement procedure}

During the experiment, the heating-stage temperatures were controlled by the software which also launched the Raman measurements (LabSpec Horiba Jobin Yvon). Room temperature spectra were recorded on all samples after insertion in the heating-stage and before the beginning of the heating experiment. The fragments were then heated to the measuring temperatures (plateau temperature) with a ramp of $50{ }^{\circ} \mathrm{C} / \mathrm{min}$ and held at this temperature during 4,6 or $13 \mathrm{~h}$. As soon as the maximum temperature was reached, a spectrum was acquired every minute. After the first $15 \mathrm{~min}$ of this temperature plateau, spectra were acquired every $5 \mathrm{~min}$ and after $1 \mathrm{~h}$, every $10 \mathrm{~min}$ (measurements with $10 \mathrm{~mW}$ excitation) or $20 \mathrm{~min}$ (measurements with $3 \mathrm{~mW}$ excitation). Measuring temperatures and durations for each sample are summarised in Table 1. 
A second room temperature spectrum was recorded after stage cooling and before removal of the samples from the heating stage.

\section{Results and discussion}

\section{Mineralogical composition and structure of the samples}

The thin sections of all three samples reveal them to be mainly composed of length-fast chalcedony. Sample PS-09-04 also contains dispersed calcite remnants from before the silicification of the chalk host rock (about $4 \%$ as semi-quantitatively determined by XRD). Sample PS-09-25 contains detrital quartz grains in its chalcedony matrix that can be estimated by thin section microscopy to 3-5\% of the total rock but no calcite. Sample VC-12-01 also contains length-slow chalcedony, the proportion of which could be estimated by thin section microscopy to $15 \%$ of the rock and dispersed opal-CT lepidospheres can be observed. Rietveld refinement of the powder diffraction data yielded moganite contents of about 10,7 and $5 \%$ for samples PS09-04, PS-09-25 and VC-12-01, respectively. Silanol contents range between 0.56 and $0.69 \mathrm{wt} \%$, water contents between 0.33 and $0.56 \mathrm{wt} \%$ and volumes of pore space in the samples ranges between 0.65 and $0.83 \mathrm{wt} \%$. The $\mathrm{SiOH}$ and $\mathrm{H}_{2} \mathrm{O}$ values obtained by IR spectroscopy are summarised in Table 1. Thus, all three samples are typical varieties of flint and chert of mixed composition, containing different types of chalcedony, moganite, opal-CT and minor amounts of calcite. Their "water" and porosity contents also fall within the range of typical values for flint and chert. Thus, our three samples are mineralogically representative of flint and fine chalcedony containing chert in general, and they reflect the slight variations between different geological sources that were used for raw material procurement at different periods.

\section{Room temperature Raman measurements}

Raman spectra acquired before the heating experiments show the quartz band at $464 \mathrm{~cm}^{-1}$ and an additional band at $503 \mathrm{~cm}^{-1}$ caused by the Si-O vibration of silanol (Fig. 1). This latter band must be expected to contain a contribution of the moganite band at $501 \mathrm{~cm}^{-1}$ caused by the samples moganite content. The comparison between room temperature spectra acquired before and after heating to the different measuring temperatures shows a decrease in the $503 \mathrm{~cm}^{-1}$ band intensity after heating (Fig. 1a) underlining the dehydroxylation reaction. This decrease of the $503 \mathrm{~cm}^{-1}$ band is more pronounced for samples heated to higher temperatures (Fig. 1a) as can be expected (Schmidt et al. 2011).

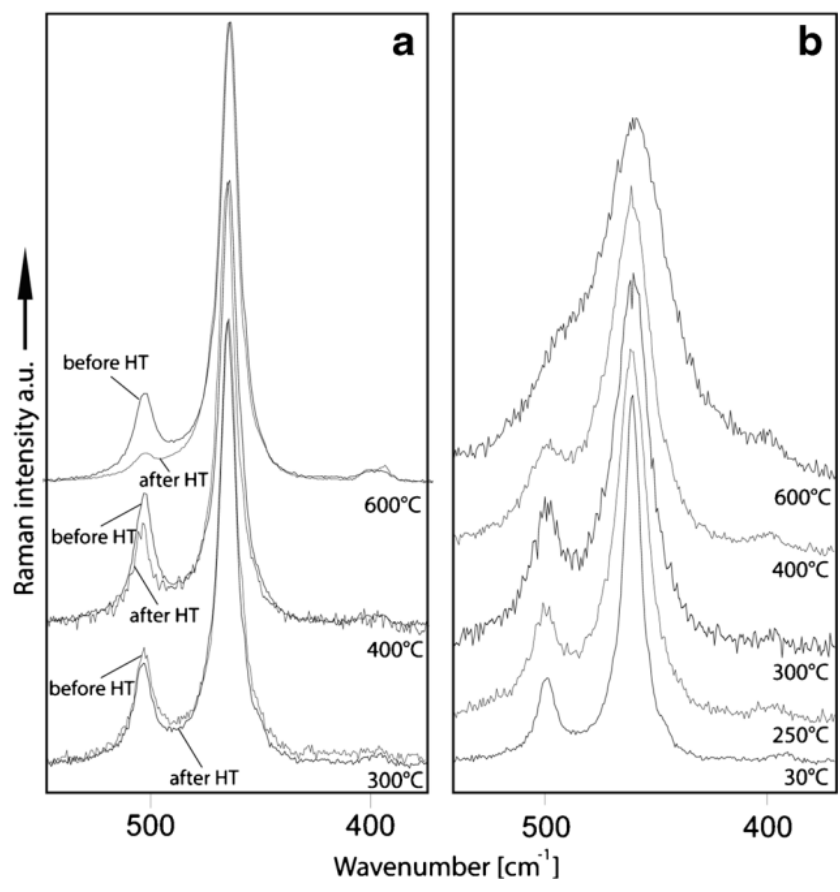

Fig. 1: Room-temperature- and in situ-Raman spectra of PS-09-04 in the analysed spectral range. Band intensities are normalised with respect to the $464 \mathrm{~cm}^{-1}$ band. a) Room-temperature spectra before and after heating to 300,400 , and $600{ }^{\circ} \mathrm{C}$ (HT heat treatment). Note the relative intensity loss of the $503 \mathrm{~cm}^{-1}$ band that is stronger after heating to higher temperatures. b) Comparison of spectra acquired in situ, just after the reaching of the indicated plateau temperature. Note the broadening of both bands that increases with rising temperature.

\section{Reaction kinetics}

At the measuring temperatures, the two Raman bands shift to lower wavenumbers as described by Schmidt et al. (2012a) and their breadth increases (Fig. 1b). Results of the time-resolved in situ measurements of the $503 \mathrm{~cm}^{-1}$ band relative intensity $\left(503 / 464 \mathrm{~cm}^{-1}\right.$ ratio) at different temperatures are shown in Figs. 2, 3 and 4 for samples PS09-04, VC-12-01 and PS-09-24, respectively. The $250{ }^{\circ} \mathrm{C}$ measurements of PS-09-04 and the $300{ }^{\circ} \mathrm{C}$ measurement of PS-09-25 did not produce any loss of the $503 / 464 \mathrm{~cm}^{-1}$ ratio outside of the calculated error, indicating that the minimum activation temperature for reaction (1) is not the same in different samples. All other measurements yielded similar results: Heating produces the loss of the 503/464 $\mathrm{cm}^{-1}$ ratio indicating the formation of $\mathrm{Si}-\mathrm{O}-\mathrm{Si}$ bonds. Best fits of the so-obtained kinetics curves are all negative logarithmic functions. Logarithmic factors of these best fits and magnitudes of the relative $503 \mathrm{~cm}^{-1}$ band-losses are summarised in Table 2.

The magnitude of the band loss is not the same in different samples and for different temperatures. However, there is no correlation with the heating temperature. Starting values of the ratio, measured directly after reaching the plateau temperature, are also not consistent in different samples, and no correlation with the heating temperature is observed. This is not unexpected because 

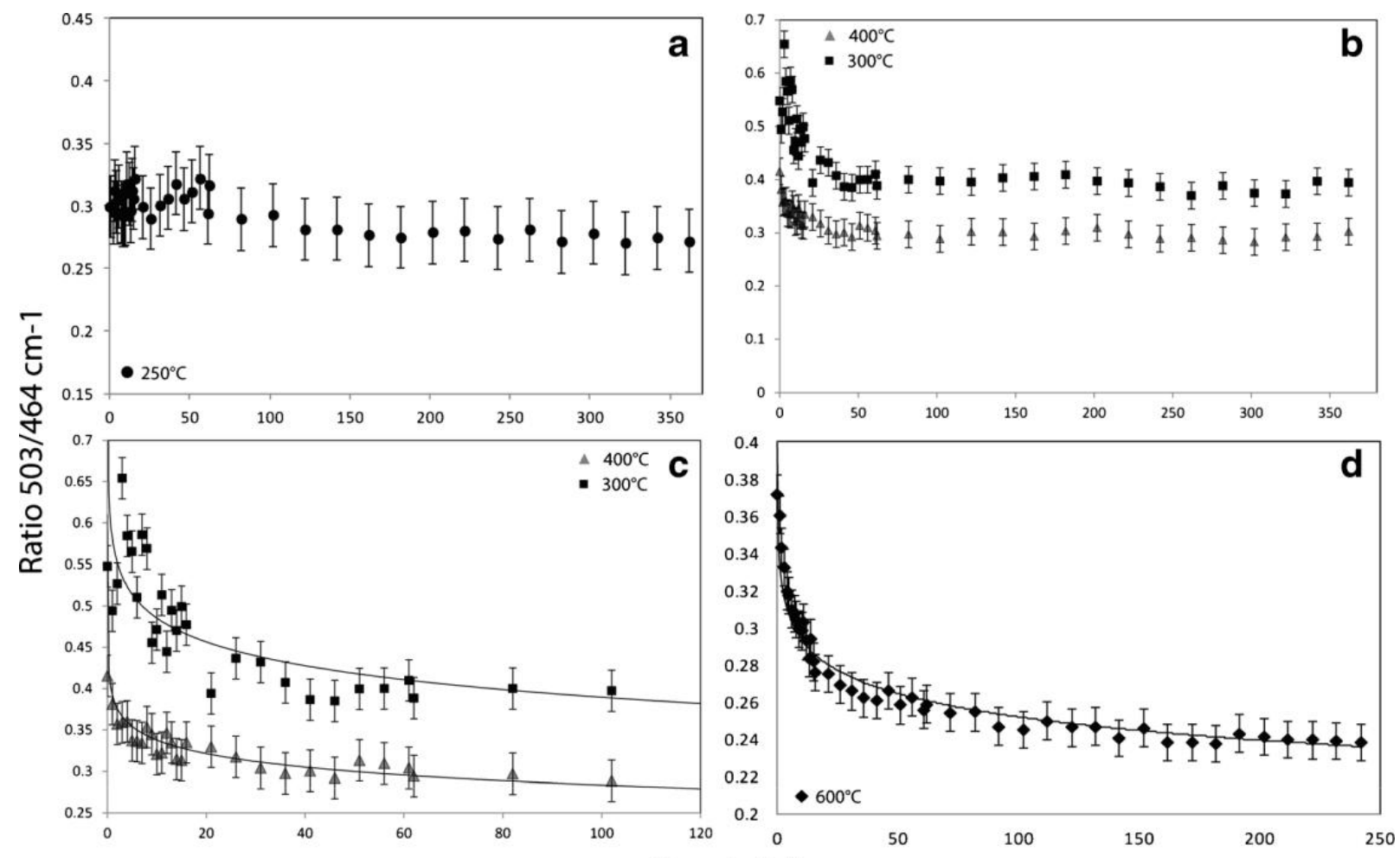

Fig. 2: Data of the time-resolved measurements showing the relative SiOH-Raman-band intensity loss for PS-09-04. The black continuous lines are the logarithmic best fits. Logarithmic factors of all measurements are given in Table 2. a) Data of the $250{ }^{\circ} \mathrm{C}$ measurement.

both these values (starting value and magnitude of the band loss) depend on several factors that were different for all measurements: the time needed to reach the plateau temperature (which initiates reaction (1) before the plateau, inducing an intensity loss not measured by our protocol), the local $\mathrm{SiOH}$ concentration assessed by the $\approx 4 \mu \mathrm{m}$ large sampling spot, the varying band breadths (compare in Fig. 1b) and Raman tensors at different temperatures. Hence, only the shape of the kinetics curve describing the progression of reaction (1) as a function of time can be regarded as significant.

It is noteworthy that during all measurements, $\mathrm{SiOH}$ loss takes place in the first hour of heating and, although the logarithmic factors of the best fits are slightly different for all measurements, the overall shape of the kinetics curves is very similar. Logarithmic factors show the tendency to decrease at higher temperatures. The reason for this may be that at higher heating temperature, more early data points of the theoretical curves are lost because reaction (1) is already active during the heating ramp but cannot be measured.

\section{Reaction mechanism}

Our results highlight that, even though the activation temperature of the formation of new $\mathrm{Si}-\mathrm{O}-\mathrm{Si}$ bonds in sedimentary chalcedony of flint and chert is not the same in different samples (Schmidt et al. 2011, 2012b), the reaction kinetics is identical in one regard: the progression of the

Note that heating to $250{ }^{\circ} \mathrm{C}$ does not produce any significant intensity loss of the $503 \mathrm{~cm}^{-1}$ band outside of the estimated measuring error. b) 300 and $400{ }^{\circ} \mathrm{C}$ data. c) Enlargement of the first 120 min of the 300 and $400{ }^{\circ} \mathrm{C}$ measurements. d) Data of the $600{ }^{\circ} \mathrm{C}$ measurement.

reaction describes a negative logarithmic curve with a factor close to $y=-0.03 \ln (x)$. This means that the large majority of the heat-induced transformations are totally or almost totally achieved after $1 \mathrm{~h}$ of heating, regardless of the heating temperature. The slightly different mineralogical composition (presence of opal-CT or calcite in some samples but not in others) does not influence the reaction kinetics. $\mathrm{H}_{2} \mathrm{O}$ and $\mathrm{SiOH}$ contents that differ in the range of values measured for the three samples or inner sample heterogeneities, as assessed by the $\approx 4 \mu \mathrm{m}$ large laser spot, also do not influence the progression of reaction (1). These results are independent of the samples' volume because the Raman measurements were acquired on the sample surface and describe the progression of the chemical reaction, not the evacuation of water from the bulk of the samples which is affected by volume effects. Thus, Fukuda and Nakashima's (2008) result on the thermal behaviour of hydrothermal chalcedony can be extended to sedimentary chalcedony of flint and chert as well. The $\mathrm{SiOH}$ "dehydration" mechanism and kinetics appear to be identical or at least very similar in all types of chalcedony, whether they occur pure or intermixed with different mineral phases. We further complement Fukuda and Nakashima's data through our measurements at different temperatures, by showing that the progression of the reaction describes a negative logarithmic function and that, in this respect, the samples behave the same way regardless of the heating temperature and sample properties. 

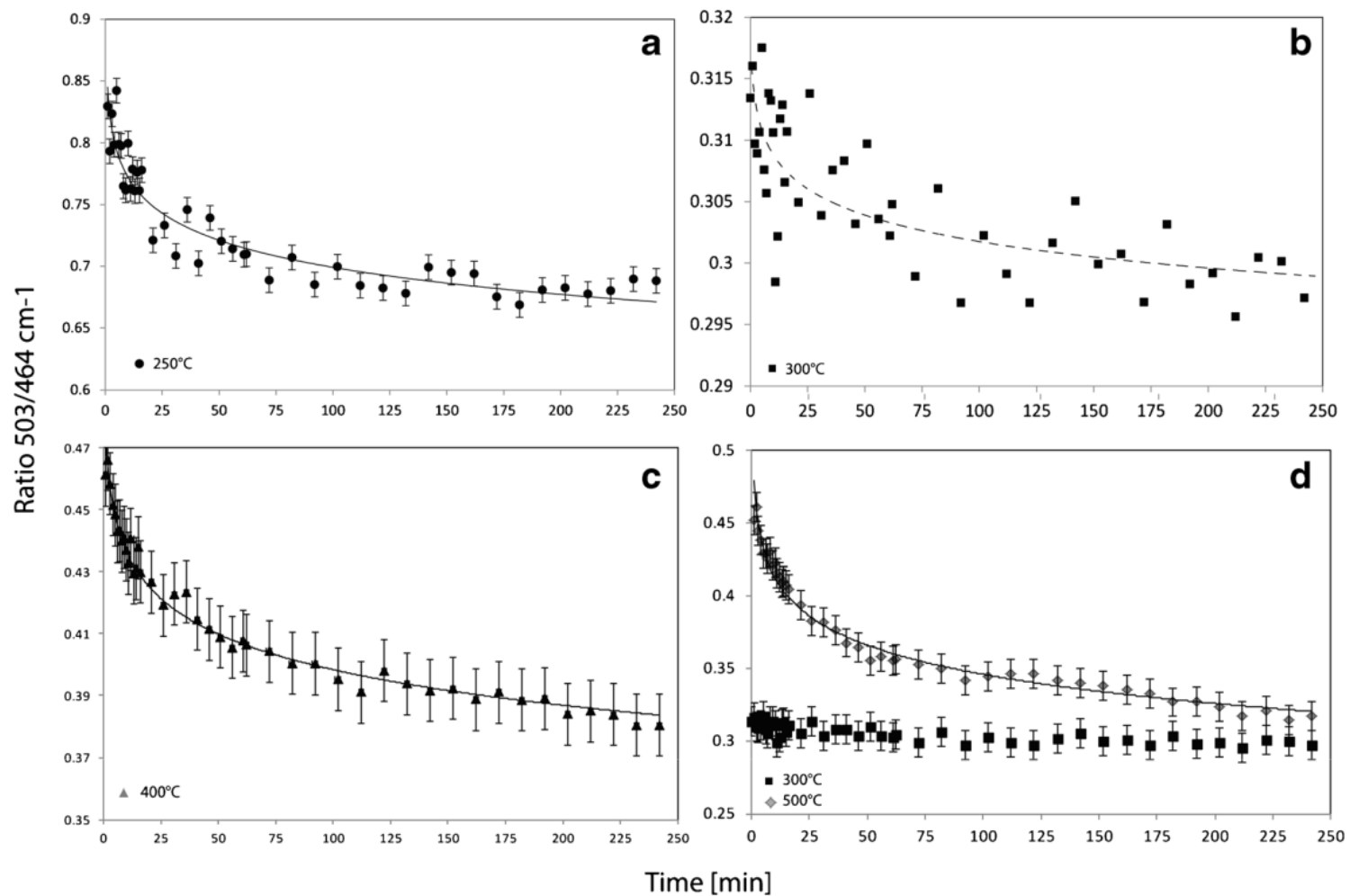

Fig. 3: Data of the time-resolved measurements showing the relative $\mathrm{SiOH}-$ Raman-band intensity loss for VC-12-01. The black continuous lines are the logarithmic best fits. Logarithmic factors of all measurements are given in Table 2. a) Data of the $250{ }^{\circ} \mathrm{C}$ measurement. b) The $300{ }^{\circ} \mathrm{C}$ measurement does not produce an intensity loss outside of the estimated measurement error (another view of this data as compared to the $500{ }^{\circ} \mathrm{C}$ measurement is shown in $\mathrm{d}$. When tentatively applied, the best fit (black broken line) has a logarithmic factor of $y=-0.03 \ln (x)$. c) $400^{\circ} \mathrm{C}$ data and d) comparison between $500{ }^{\circ} \mathrm{C}$ data and $300{ }^{\circ} \mathrm{C}$ data.
The only prerequisite is that this temperature is higher than the minimum activation temperature required for the silanol loss which varies between 200 and $300{ }^{\circ} \mathrm{C}$ in different samples (Schmidt et al. 2011, 2012b).

\section{Implications for lithic heat treatment}

Combining our results with previously published data, we can try to estimate the investment in time needed for heat treatment of flint and fine chalcedony containing chert.

Parameter (1) the first parameter relevant for this estimation, the heating speed or ramp rate, is a function of the content of $\mathrm{H}_{2} \mathrm{O} / \mathrm{SiOH}$ and the ability of the heat-treated rock to evacuate this bulk water through its network of open pores (Schmidt 2014). For flint and chert, this relation imposes relatively slow heating speeds. For example, a volume of $37 \mathrm{~cm}^{3}$ of flint, containing $\approx 0.8 \mathrm{wt} \% \mathrm{SiOH}$ and $\approx 0.8$ vol\% pores, cannot be heated to $350{ }^{\circ} \mathrm{C}$ with a ramp rate faster than $0.1^{\circ} \mathrm{C} / \mathrm{min}$ without overheating, while a volume of $12 \mathrm{~cm}^{3}$ can be heated with $0.5^{\circ} \mathrm{C} / \mathrm{min}$ (Schmidt 2014). Thus, heating speed is not a constant and cannot be estimated without precise knowledge of the crystallography, structure and volume of the heat-treated rocks.
However, there can be no doubt that flint and chert require relatively slow heating rates: a range of ramp rates between 0.1 and $1{ }^{\circ} \mathrm{C} / \mathrm{min}$ appears a realistic approximation for most flint and chert with volumes smaller than $100 \mathrm{~cm}^{3}$ (based on the experimental data in Schmidt (2014) and the crystallographic data of several flint and chert samples in Schmidt et al. (2011)). This need for slow heating speeds explains the ethnographic observations describing heat treatment in a dedicated heating environment like ashes, a sand bath beneath a fire (Hester 1972) or a container creating an oven-like environment (Kenoyer et al. 1991). It appears very likely that heat treatment of flint and chert in prehistoric times also relied on the use of dedicated heating environments producing slow ramp rates.

Parameter (2) the maximum heating temperature, can be estimated based on data from Schmidt et al. (2011, 2012b, 2013a). Flint and chert must be heated to at least $200{ }^{\circ} \mathrm{C}$, or even $300^{\circ} \mathrm{C}$ depending on the sample, for the treatment to be effective (Schmidt et al. 2011, 2012b). The reason for this is the minimum activation energy needed for $\mathrm{SiOH}$ dehydration that was measured close to $200{ }^{\circ} \mathrm{C}$ in some samples (Schmidt et al. 2013c) and close to $250{ }^{\circ} \mathrm{C}$ or even $300{ }^{\circ} \mathrm{C}$ in others (Schmidt et al. 2011). On the other hand, the maximum temperature $\left(\mathrm{T}_{\max }\right)$ for flint and chert heat treatment is close to $450{ }^{\circ} \mathrm{C}$ (Schmidt et al. 2012b). 


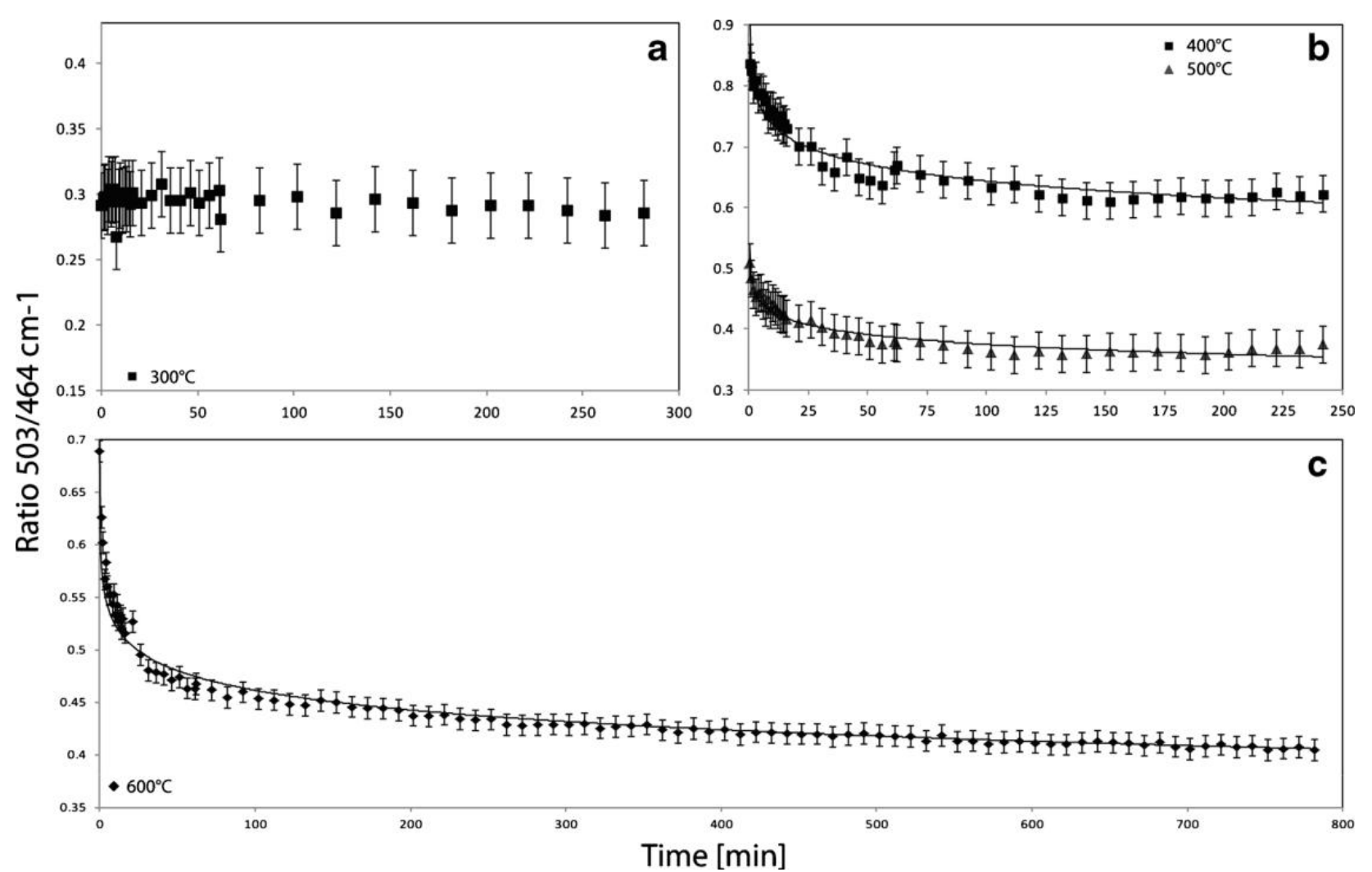

Fig. 4: Data of the time-resolved measurements showing the relative SiOH-Raman-band intensity loss for PS-09-25. The black continuous lines are the logarithmic best fits. Logarithmic factors of all measurements are given in Table 2. a) Data of the $300{ }^{\circ} \mathrm{C}$ measurement. Note that heating to $300{ }^{\circ} \mathrm{C}$ does not produce any intensity loss of the $503 \mathrm{~cm}^{-1}$ band outside of the estimated error.

b) Comparison between $400{ }^{\circ} \mathrm{C}$ data and $500{ }^{\circ} \mathrm{C}$ data. Note the different starting values of the curves at $0 \mathrm{~min}$, just after the reaching of the plateau temperature. c) Data of the long measurement at $600{ }^{\circ} \mathrm{C}$. Note that even prolonged heating for up to $13 \mathrm{~h}$ does not produce significantly more band-loss than heating for $4 \mathrm{~h}$.

At higher temperatures, even the smallest samples fracture internally and become useless for knapping (Schmidt et al. 2011). Thus, the potentially useful range of temperatures for flint and chert lies between 200 and $450{ }^{\circ} \mathrm{C}$. However, the exact limits of this range for a given sample depend on

the same factors as the ramp rate $\left(\mathrm{H}_{2} \mathrm{O} / \mathrm{SiOH}\right.$ content, porosity, volume). It must be expected that large samples with a high water content and little pore space cannot be heated to the higher end of this range (Schmidt 2014). This relation is best illustrated by the example of heat treatment during the Neolithic Chassey culture where large preforms

Table 2: Relative band loss of the $\mathrm{SiOH}$ Raman band (as expressed by the $503 / 464 \mathrm{~cm}^{-1}$ ratio) measured in situ during heat treatment to different temperatures.

\begin{tabular}{llllll}
\hline Sample & $\begin{array}{l}\text { Plateau heating } \\
\text { temperature }\end{array}$ & $\begin{array}{l}\text { Initial ratio at plateau } \\
\text { temperature }\end{array}$ & $\begin{array}{l}\text { Ratio at the end of } \\
\text { the heating plateau }\end{array}$ & $\Delta$ ratio & $\begin{array}{l}\text { Logarithmic factor } \\
\text { of the best fit }\end{array}$ \\
\hline PS-09-04 & $250{ }^{\circ} \mathrm{C}$ & $0.257 \pm 0.02$ & $0.241 \pm 0.02$ & - & - \\
PS-09-04 & $300^{\circ} \mathrm{C}$ & $0.547 \pm 0.02$ & $0.395 \pm 0.02$ & 0.152 & $\mathrm{y}=-0.042 \ln (\mathrm{x})$ \\
PS-09-04 & $400^{\circ} \mathrm{C}$ & $0.416 \pm 0.02$ & $0.303 \pm 0.02$ & 0.116 & $\mathrm{y}=-0.024 \ln (\mathrm{x})$ \\
PS-09-04 & $600^{\circ} \mathrm{C}$ & $0.372 \pm 0.01$ & $0.239 \pm 0.01$ & 0.133 & $\mathrm{y}=-0.02 \ln (\mathrm{x})$ \\
VC-12-01 & $250^{\circ} \mathrm{C}$ & $0.804 \pm 0.01$ & $0.688 \pm 0.01$ & 0.116 & $\mathrm{y}=-0.032 \ln (\mathrm{x})$ \\
VC-12-01 & $300^{\circ} \mathrm{C}$ & $0.313 \pm 0.01$ & $0.297 \pm 0.01$ & - & - \\
VC-12-01 & $400{ }^{\circ} \mathrm{C}$ & $0.464 \pm 0.01$ & $0.38 \pm 0.01$ & 0.083 & $\mathrm{y}=-0.017 \ln (\mathrm{x})$ \\
VC-12-01 & $500^{\circ} \mathrm{C}$ & $0.471 \pm 0.01$ & $0.317 \pm 0.01$ & 0.154 & $\mathrm{y}=-0.029 \ln (\mathrm{x})$ \\
PS-09-25 & $300^{\circ} \mathrm{C}$ & $0.291 \pm 0.02$ & $0.285 \pm 0.02$ & - & - \\
PS-09-25 & $400^{\circ} \mathrm{C}$ & $0.837 \pm 0.01$ & $0.622 \pm 0.01$ & 0.215 & $\mathrm{y}=-0.04 \ln (\mathrm{x})$ \\
PS-09-25 & $500^{\circ} \mathrm{C}$ & $0.51 \pm 0.01$ & $0.375 \pm 0.01$ & 0.135 & $\mathrm{y}=-0.023 \ln (\mathrm{x})$ \\
PS-09-25 & $600^{\circ} \mathrm{C}$ & $0.561 \pm 0.01$ & $0.324 \pm 0.01$ & 0.238 & $\mathrm{y}=-0.027 \ln (\mathrm{x})$ \\
\hline
\end{tabular}

Initial ratio values were measured directly after reaching the maximum heating temperature. End ratio values were measured in the end of the heating plateau before cooling of the heating stage. $\Delta$ ratio is the difference between initial and end values. 
of flint (Léa 2005) with 0.6-0.9 vol\% pore space (Schmidt et al. 2013a) were heated to temperatures between 200 and $250{ }^{\circ} \mathrm{C}$ (Schmidt et al. 2013a). In contrast, smaller volumes of flint or chert with less water and more pore space may be heated to temperatures closer to $450^{\circ} \mathrm{C}$.

Parameter (3) the time the stones must be held at $\mathrm{T}_{\max }$, does not impose a significant supplementary investment in time as underlined by the kinetics studied in the present work. After $1 \mathrm{~h}$ of heating, most of the desired transformations in the rocks are terminated, and further heating only produces a very small supplementary effect. Only rising of $T_{\max }$ intensifies the effect of the heat treatment. The negative logarithmic shape of the kinetics curve implies further that already after a relatively short time of heating, a relatively large effect is produced. Between 55 and $65 \%$ of the heat-induced transformations that can take place in $1 \mathrm{~h}$ at the $\mathrm{T}_{\max }$ are already achieved after $10 \mathrm{~min}$ (as calculated from the time-resolved measurements made during our kinetics study). However, these percentages are estimated based on our heating protocol using a ramp rate of $50^{\circ} \mathrm{C} / \mathrm{min}$. When flint or chert is heat-treated with a slower heating rate, a substantial part of the transformations already takes place before the rock even reaches the maximum temperatures. Eriksen (1997) used ramp rates between 0.2 and $0.9{ }^{\circ} \mathrm{C} / \mathrm{min}$ for heat treatment of chert in sand beneath a fire. When heating with ramp rates of this order of magnitude, a large part of the transformations is already achieved before the stone reaches $T_{\max }$. For example, using a ramp rate of 0.2 ${ }^{\circ} \mathrm{C} / \mathrm{min}$, the heat treatment temperature is increased by only $10^{\circ} \mathrm{C}$ every $50 \mathrm{~min}$. This means that, once $T_{\max }$ is reached, almost the entire silanol that can be dehydrated at $T_{\max }$ minus $10^{\circ} \mathrm{C}$ is already dehydrated. Thus, even if the stone is not held at $T_{\max }$ at all, but the cooling begins immediately after reaching $\mathrm{T}_{\max }$, the largest part of $\mathrm{Si}-\mathrm{O}-\mathrm{Si}$ formation is achieved when such a slow heating rate is used.

Parameter (4) concerning the cooling rate, no explicit experimental data on flint or chert is available. Some authors (Griffiths et al. 1987; Micheelsen 1966) have observed that very fast cooling, as its occurs when the door of an electrical furnace is opened at $T_{\max }$, produces failure of flint, but the fastest possible cooling rate that prevents flint and chert from failing is unknown. However, the data published by several authors allow to estimate the effective cooling rates produced by different heating environments. The data of Eriksen (1997) for example indicate average cooling rates between $\approx 10$ and $22{ }^{\circ} \mathrm{C} / \mathrm{h}$ for heat treatment

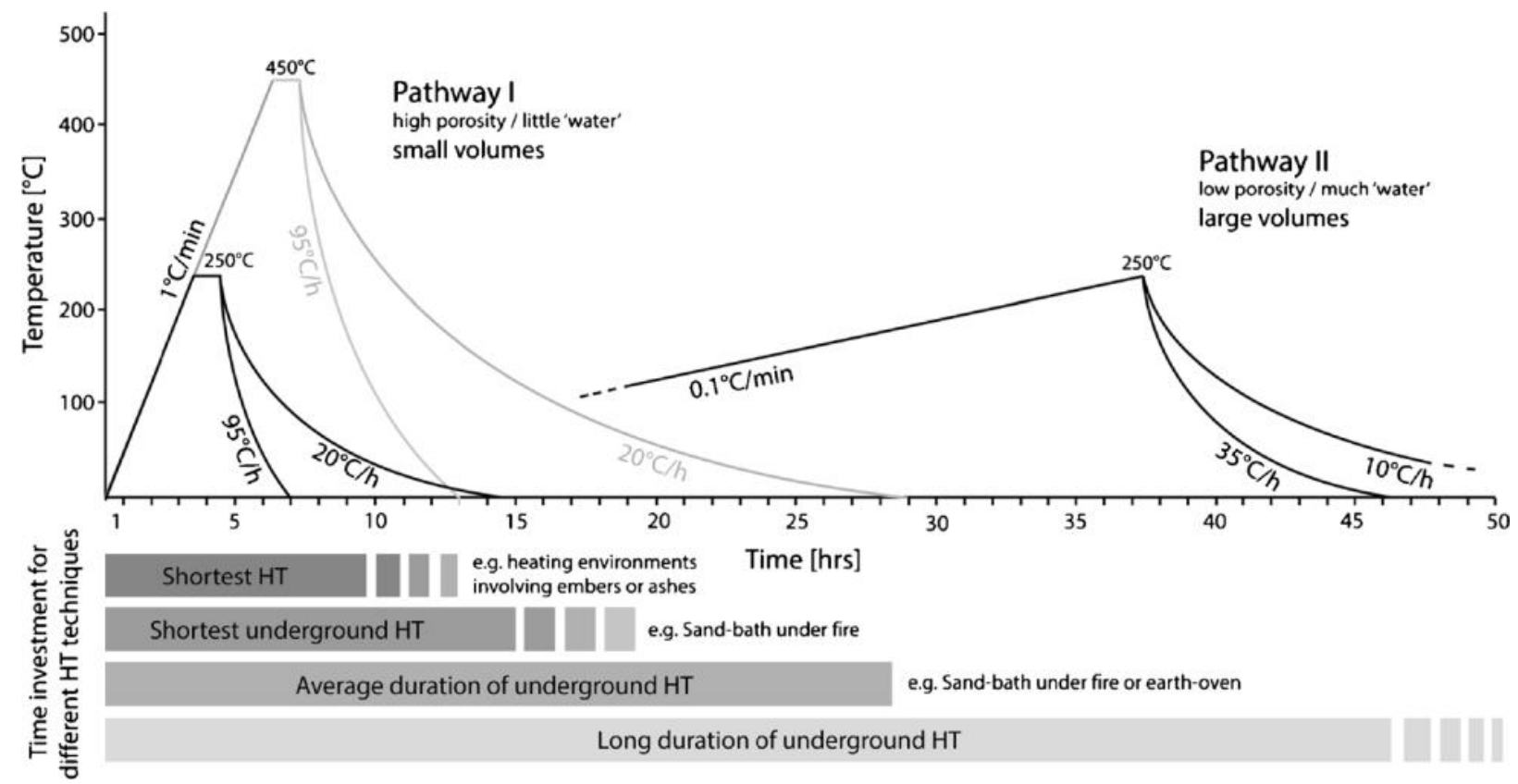

Fig. 5: Schematic overview showing the investment in time needed for heat treatment of flint and chert. Pathway I describes the fastest possible procedure that is only applicable to small rocks with low contents of chemically bound water and large pore spaces allowing good water evacuation. Maximum temperatures range between 250 and $450{ }^{\circ} \mathrm{C}$, and the fastest possible heating speed is estimated to $\approx 1{ }^{\circ} \mathrm{C} / \mathrm{min}$, as discussed in "Implications for lithic heat treatment". During this pathway, stones must be held at maximum temperature for no longer than $1 \mathrm{~h}$. The fastest cooling rate of pathway I corresponds to the effective cooling speed of embers in a burned down fires. The slower cooling rate of $20{ }^{\circ} \mathrm{C} / \mathrm{h}$ corresponds to an intermediate cooling speed of sediment beneath a burned down fire. Pathway II describes heat treatment of larger volumes of rocks with high contents of chemically bound water and less pore space. Such rocks cannot be heated to temperatures much higher than $250{ }^{\circ} \mathrm{C}$, and the slow heating rates make a plateau at maximum temperature before cooling unnecessary.
Because heating environments that produce such slow heating rates also impose slow cooling rates, the fastest rate of pathway II corresponds to rapid cooling of sediment beneath a burned out fire, and the slower rate corresponds to slowly cooling sediment beneath a burned out fire. The bars in the lower part of the graph show examples of durations of different heat treatment techniques. The fastest procedure of $\approx 7-13 \mathrm{~h}$ can only be conducted with rocks containing large pores and little water. Such rocks also need to be heated to temperatures higher than $300{ }^{\circ} \mathrm{C}$ for the treatment to be effective. A heating environment involving contact of the rocks with embers or ashes seems to be prerequisite for such a fast procedures. The shortest and average durations of underground heating describe the length of sand bath heating of rocks with different volumes. The long duration of underground HT describes the investment in time needed for heating of large volumes of fine flint or chert. 
in a sand bath beneath a fire, and Mandeville and Flenniken (1974) describe cooling rates of $\approx 13^{\circ} \mathrm{C} / \mathrm{h}$ for heat treatment in an earth oven-like structure. The data published by Bentsen (2013) allow to estimate average cooling rates between $\approx 20$ and $34{ }^{\circ} \mathrm{C} / \mathrm{h}$ in the sediment below different fires made from various wood types. Bentsen's work also allows to estimate the effective cooling rate directly within the dying fires to between $\approx 43$ and $95^{\circ} \mathrm{C} / \mathrm{h}$. Because an appropriate heating environment must be chosen as a function of the conditions needed for each type of flint or chert (for example to ensure slow heating rates for rocks with high water content and little pore space), this environment will also influence the cooling rates and therefore the total time required for heat treatment. Unless any action is undertaken to "extract" the rock, each environment also imposes a specific cooling rate when the heat source is burned out. It is therefore not the fastest cooling rate tolerated by flint or chert that is of importance for estimating the total investment in time required for their heat treatment, but rather the time imposed by different heating environments is important. Thus, because most flint and chert cannot be heated directly in a fire (excessive heating rates would cause overheating), the heating environments that must be used for the treatment normally produce cooling rates not faster than $40^{\circ} \mathrm{C} / \mathrm{h}$.

\section{Conclusion}

Our analyses of the thermal transformations' reaction kinetics in flint and chert showed that these types of rock do not need to be held at maximum temperature for longer than $1 \mathrm{~h}$. Even significantly shorter times at $\mathrm{T}_{\max }$ produce rather intense transformations. Once the minimum activation temperature is reached, this need for relatively short plateau-heating durations is independent of the heat treatment temperature and appears to be very similar in different samples, regardless of their mineralogy. However, in order to estimate the duration of the complete heat treatment procedure, not only this plateau-heating duration must be known. The total time of the procedure can only be understood as the addition of three stages (ramp, plateau and descent), the length of which is governed by four heating parameters (ramp rate, maximum temperature, plateau-heating duration and cooling rate). Our discussion of these four parameters taken together allows to propose theoretical boundaries of the total time needed for heat treatment. Depending on the volume, mineralogy and structure of the heated samples, two extremes, limiting the time span required by heat treatment, can be considered (shortest and longest). The actual time of the treatments performed in archaeological times can be supposed to lie within these limits. A graphical synthesis of these results is shown in Fig. 5. It can be seen from this figure that the investment in time necessary for heat-treating rocks like flint and chert ranges from approximately $7 \mathrm{~h}$, if a heating environment like glowing embers is used to heat small volumes of rock with little water and much pore space, to more than 2 days, if large volumes of stone with much water and few pore space are heated underground or in an oven-like heating environment. The actual time needed for heat treatment of a given rock must be expected to lie somewhere in-between these two extremes and depends on the used heating environment. The determination of the effective duration of different archaeological thermal treatment procedures must further rely on tangible archaeological finds that corroborate the theoretical consideration on the heating parameters. These finds include the evaluation of the size of heated blocks and the structural and mineralogical characterisation of the heated type of rock, which both allow to investigate the necessary and tolerated temperatures and ramp rates. On the other hand, the discovery of specific heating structures that can be linked to heat treatment of lithic raw materials will refine our understanding of the management of these constraints and the duration of the process.

Can our results also be applied to heat-treated silcrete? At the current state of knowledge, this question cannot be answered with certainty. It may be expected that the thermal transformations' reaction kinetics are the same in micro-quartz bearing silcrete as in chalcedony dominated flint and chert, but no experimental data is yet available to prove it. In any case, the total investment in time needed for silcrete heat treatment is significantly shorter than for flint and chert (Schmidt et al. 2015) because, at least, the heating rate can be significantly faster (Schmidt et al. 2013b). The time samples need to be held at maximum temperature would thus be a relatively more important parameter for the silcrete heating procedure than for flint and chert.

Acknowledgments We thank the Deutsche Forschungsgemeinschaft (DFG) for funding of the research project Heat Treatment in the South African MSA that made part of the present study possible (Grant Nr: CO 226/25-1, MI 1748/2-1, NI 299/25-1). We also thank S. Puaud from the Muséum national d'histoire naturelle, Dpt. de Préhistoire UMR 7194, for his collaboration to the acquisition of the powder diffraction data. We also thank V. Léa and Ph. Sciau for providing sample VC-12-01.

\section{References}

Aubry T, Walter B, Robin E, Plisson H, Benhabdelhadi M (1998) Le site solutréen des Maîtreaux (Bossay-surClaise, Indre-et-Loire): un faciès original de production lithique. Paléo 10:163-184

Bentsen SE (2013) Controlling the heat: an experimental approach to Middle Stone Age pyrotechnology. S Afr Archaeol Bull 68:137- 145

Binder D (1984) Systèmes de débitage laminaire par pression: exemples chasséens provençaux. In: Tixier J, Inizan ML, Roche $\mathrm{H}$ (eds) Préhistoire de la pierre taillée, 2: économie du débitage laminaire: technologie et expérimentation: Ille table ronde de technologie lithique. Meudon-Bellevue, octobre 1982. Cercle de Recherches et d'Etudes Préhistoriques, Paris, pp 71-84

Bordes F (1969) Traitement thermique du silex au Solutréen. Bulletin de la Société préhistorique française 66:197 
Brown KS, Marean CW, Herries AIR, Jacobs Z, Tribolo C, Braun D, Roberts DL, Meyer MC, Bernatchez J (2009) Fire as an engineering tool of early modern humans. Science 325:859 862

Crabtree DE, Butler BR (1964) Notes on experiment in flint knapping: 1 heat treatment of silica materials. Tebiwa 7:1-6

Eriksen BV (1997) Implications of thermal pre-treatment of chert in the German Mesolithic. In: Schild R, Sulgostowska Z (eds) Man and Flint, Proceedings of the VII International Flint Symposium Warszawa-Ostrowiec Swietokrzyski, September 1995. Institute of Archaeology and Ethnology Polish Academy of Sciences, Warsaw, pp 325-329

Eriksen BV (2006) Colourful Lithics - the "Chaîne Opératoire" of Heat Treated Chert Artefacts in the Early Mesolithic of Southwest Germany. In: Kind CJ (ed) After the Ice Age. Settlements, subsistence and social development in the Mesolithic of Central Europe, Materialhefte zur Archäologie in Baden-Württemberg. Konrad Theiss Verlag, Stuttgart, pp 147-153

Flörke OW, Köhler-Herbertz B, Langer K, Tönges I (1982) Water in microcrystalline quartz of volcanic origin: agates. Contrib Mineral Petrol 80:324-333

Flörke OW, Flörke U, Giese U (1984) Moganite, a new microcrystalline silica-mineral. Neues $\mathrm{Jb}$ Mineral Abh 149:325-336

Fukuda J, Nakashima S (2008) Water at high temperatures in a micro-crystalline silica (chalcedony) by in-situ infrared specroscopy: physicochemical states and dehydration behavior. J Mineral Petrol Sci 103:112-115

Fukuda J, Peach CJ, Spiers CJ, Nakashima S (2009) Electrical impedance measurement of hydrous microcrystalline quartz. $J$ Mineral Petrol Sci 104:176-181

Götze J, Nasdala L, Kleeberg R, Wenzel M (1998) Occurrence and distribution of "moganite" in agate/chalcedony: a combined micro-Raman, Rietveld, and cathodoluminescence study. Contrib Mineral Petrol 133:96-105

Graetsch H, Flörke OW, Miehe G (1985) The nature of water in chalcedony and opal-C from brazilian agate geodes. Phys Chem Miner 12: 300-306

Griffiths DR, Bergman CA, Clayton CJ, Ohnuma K, Robins GV (1987) Experimental investigation of the heat treatment of flint. In: Sieveking GG, Newcomer MH (eds) The human uses of flint and chert. Proceedings of the fourth international flint symposium held at Brighton Polytechnic 10-15 April 1983. Cambridge University Press, Cambridge, pp 43-52

Heaney PJ, Post JE (1992) The widespread distribution of a novel silica polymorph in microcrystalline quartz varieties. Science 255:441- 443

Heaney PJ, Post JE (2001) Evidence for an I2/a to Imab phase transition in the silica polymorph moganite at $\sim 570 \mathrm{~K}$. Am Mineral 86:1358-1366

Hester TR (1972) Ethnographic evidence for the thermal alteration of siliceous stone. Tebiwa 15:63-65

Kenoyer JM, Vidale M, Bhan KK (1991) Contemporary stone bead making in Khambhat, India: patterns of craft specialisation and organisation of production as reflected in the archaeological record. World Archaeol 23:45-63

Kingma KJ, Hemley RJ (1994) Raman spectroscopic study of microcrystalline silica. Am Mineral 79:269-273

Léa V (2005) Raw, pre-heated or ready to use: discovering specialist supply systems for flint industries in mid-Neolithic (Chassey culture) communities in southern France. Antiquity 79:1-15

Lutterotti $L$ (2010) Total pattern fitting for the combined size-strainstress-texture determination in thin film diffraction. Nucl Inst Methods Phys Res B 268:334-340

Mandeville MD, Flenniken J (1974) A comparison of the flaking qualities of Nehawka chert before and after thermal pretreatment. Plains Anthropol 19:146-148
Mercieca A (2000) An experimental study of heat fracturing in silcrete. Aust Archaeol 51:40-47

Mercieca A, Hiscock P (2008) Experimental insights into alternative strategies of lithic heat treatment. J Archaeol Sci 35:26342639

Micheelsen H (1966) The structure of dark flint from Stevns, Denmark. Medd Dansk Geol Foren 16:285-368

Miehe G, Graetsch H (1992) Crystal structure of moganite: a new structure type of silica. Eur J Mineral 4:693-706

Mourre V, Villa P, Henshilwood CS (2010) Early use of pressure flaking on lithic artifacts at Blombos cave, South Africa. Science 330:659- 662

Porraz G, Texier P-J, Archer W, Piboule M, Rigaud J-P, Tribolo C (2013) Technological successions in the Middle Stone Age sequence of Diepkloof Rock Shelter, Western Cape, South Africa. J Archaeol Sci 40:3376-3400

Roqué-Rosell J, Torchy L, Roucau C, Lea V, Colomban P, Regert M, Binder D, Pelegrin J, Sciau P (2010) Influence of Heat Treatment on the Physical Transformations of Flint Used by Neolithic Societies in the Western Mediterranean, International conference, Materials Research Society, november 2010, Boston, pp. mrsf10-1319-ww1309-1302

Schmidt P (2014) What causes failure (overheating) during lithic heat treatment? Archaeol Anthropol Sci 6:107-112

Schmidt P, Badou A, Fröhlich F (2011) Detailed FT near-infrared study of the behaviour of water and hydroxyl in sedimentary length-fast chalcedony, $\mathrm{SiO}_{2}$, upon heat treatment. Spectrochim Acta A Mol Biomol Spectrosc 81:552-559

Schmidt P, Bellot-Gurlet L, Slodczyk A, Fröhlich F (2012a) A hitherto unrecognised band in the Raman spectra of silica rocks: influence of hydroxylated $\mathrm{Si}-\mathrm{O}$ bonds (silanole) on the Raman moganite band in chalcedony and flint $\left(\mathrm{SiO}_{2}\right)$. Phys Chem Miner 39:455-464

Schmidt P, Masse S, Laurent G, Slodczyk A, Le Bourhis E, Perrenoud C, Livage J, Fröhlich F (2012b) Crystallographic and structural transformations of sedimentary chalcedony in flint upon heat treatment. J Archaeol Sci 39:135-144

Schmidt P, Léa V, Sciau P, Fröhlich F (2013a) Detecting and quantifying heat treatment of flint and other silica rocks: a new non-destructive method applied to heat-treated flint from the Neolithic Chassey culture, southern France. Archaeometry 55:794-805

Schmidt P, Porraz G, Slodczyk A, Bellot-gurlet L, Archer W, Miller CE (2013b) Heat treatment in the South African Middle Stone Age: temperature induced transformations of silcrete and their technological implications. J Archaeol Sci 40(9):3519-3531

Schmidt P, Slodczyk A, Léa V, Davidson A, Puaud S, Sciau P (2013c) A comparative study of the thermal behaviour of length-fast chalcedony, length-slow chalcedony (quartzine) and moganite. Phys Chem Miner 40:331-340

Schmidt P, Bellot-Gurlet L, Léa V, Sciau P (2014) Moganite detection in silica rocks using Raman and infrared spectroscopy. Eur J Mineral 25:797-805

Schmidt P, Porraz G, Bellot-Gurlet L, Ligouis B, Paris C, Texier PJ, Parkington JE, Miller CE, Nickel KG, Conard NJ (2015) A previously undescribed organic residue sheds light on heat treatment in the Middle Stone Age. Journal of Human Evolution, http:// dx.doi.org/10.1016/j.jhevol.2015.05.001

Scholze H (1960) Über die quantitative UR-spektroskopische Wasserbestimmung in Silikaten. Fortschr Mineral 38:122-123

Tiffagom M (1998) Témoignages d'un traitement thermique des feuilles de laurier dans le Solutréen supérieur de la grotte du Parpalló (Gandia, Espagne). Paléo 10:147-161

Wilke PJ, Flenniken J, Ozbun TL (1991) Clovis Technology at the Anzick Site, Montana. J Calif Great Basin Anthropol 13:242272

Will G, Bellotto M, Parrish W, Hart M (1988) Crystal structures of quartz and magnesium germanate by profile analysis of synchrotron-radiation high-resolution powder data. J Appl Crystallogr 21:182-191 